\title{
Combination of Pretreatments with Acetic Acid and Sodium Methoxide for Efficient Digoxin Preparation from Digitalis Glycosides in Digitalis lanata Leaves
}

\author{
Yasuhiko Higashi*, Yukari Ikeda, Youichi Fujii \\ Department of Analytical Chemistry, Faculty of Pharmaceutical Sciences, Hokuriku University, Kanazawa, \\ Japan \\ Email: "y-higashi@hokuriku-u.ac.jp
}

Received 21 April 2016; accepted 28 May 2016; published 31 May 2016

Copyright (C) 2016 by authors and Scientific Research Publishing Inc.

This work is licensed under the Creative Commons Attribution International License (CC BY). http://creativecommons.org/licenses/by/4.0/

(c) (i) Open Access

\begin{abstract}
We previously developed an HPLC method for determination of lanatoside $C$, digoxin and $\alpha$-acetyldigoxin in digitalis glycosides isolated from Digitalis lanata leaves. Here, we present an improved HPLC-UV method to determine those compounds and deslanoside. We used the improved method to examine the effects of various pretreatments on the amounts of the four compounds isolated from the leaves, with the aim of maximizing the yield of digoxin. Leaves were extracted with $50 \%$ methanol, followed by clean-up on a Sep-Pak $\mathrm{C}_{18}$ cartridge prior to HPLC analysis. The amounts of lanatoside $C$, digoxin and $\alpha$-acetyldigoxin per $100 \mathrm{mg}$ of the leaves without pretreatment were 115.6, 7.45 and $23.8 \mu \mathrm{g}$, respectively (deslanoside was not detected). Pretreatment with acetic acid, which activated deglucosylation mediated by digilanidase present in the leaves, increased the amounts of digoxin and $\alpha$-acetyldigoxin, while lanatoside $C$ and deslanoside were not detected. Pretreatment with sodium methoxide, which hydrolyzed lanatoside $C$ to deslanoside, increased the yields of deslanoside and digoxin, while lanatoside $C$ and $\alpha$-acetyldigoxin were not detected. The combination of both pretreatments afforded only digoxin in a yield of $115.1 \mu \mathrm{g} / 100 \mathrm{mg}$ leaves. Use of the combined pretreatments appears to be effective for maximizing the yield of digoxin from the leaves.
\end{abstract}

\section{Keywords}

Digoxin, Lanatoside C, $\alpha$-Acetyldigoxin, Deslanoside, HPLC, Digitalis lanata, Pretreatment

\footnotetext{
${ }^{*}$ Corresponding author.
}

How to cite this paper: Higashi, Y., Ikeda, Y. and Fujii, Y. (2016) Combination of Pretreatments with Acetic Acid and Sodium Methoxide for Efficient Digoxin Preparation from Digitalis Glycosides in Digitalis lanata Leaves. Pharmacology \& Pharmacy, 7, 200-207. http://dx.doi.org/10.4236/pp.2016.75026 


\section{Introduction}

Digitalis (D.) lanata is a species of foxglove, and its name comes from the texture of the leaves like fingers of a glove. D. lanata contains various cardiac glycosides that are used to treat congestive heart failure and atrial fibrillation. Among them, digoxin (Dx) is most commonly used, and is available for per oral administration, while deslanoside (DLC, deacetyl form of lanatoside C) is used for intravenous administration. These compounds are obtained by extraction from the leaves of $D$. lanata. It is well known that lanatoside C (LC) is transformed into $\alpha$-acetyldigoxin (ADx) by deglucosylation mediated by digilanidase present in the leaves [1], and ADx is subsequently converted to digoxin by deacetylation.

We previously determined the amounts of LC and Dx in dried leaf powder of $D$. lanata by means of an HPLC-UV $(220 \mathrm{~nm})$ method using a reversed-phase $\mathrm{C}_{8}$ column [2]. Extraction was carried out by addition of 50\% methanol $(25 \mathrm{~mL})$ to the dried powder, followed by ultrasonication for $1 \mathrm{~h}$. Pretreatment with $0.05 \%$ sodium bicarbonate solution and incubation at $40^{\circ} \mathrm{C}$ gradually decreased the amount of LC and increased that of Dx, compared with the control. We also developed an HPLC method to determine ADx using the same column, and found that the ADx level was increased 10 -fold by heating the suspension in $0.05 \%$ acetic acid [3]; this pretreatment appeared to promote deglucosylation of LC to ADx by activating digilanidase. Cobb [4] used a silica gel column to assay Dx generated by enzymatic conversion of LC, followed by deacetylation with sodium hydroxide. Pekić and Miljković [5] reported conversion of LC to DLC by sodium methoxide. Based on these reports, we considered that a suitable pretreatment method or combination of methods would enable us to maximize the yield of Dx from $D$. lanata.

Several methods for assay for Dx and/or other cardiac glycosides such as DLC in biological samples have been developed using liquid chromatography/mass spectrometry [6] [7] and pulsed amperometric detection [8], but these techniques are quite complex, and require expensive equipment. On the other hand, we established Dx immunoassays using highly specific antisera [9]-[12], but since these are specific for Dx, the amounts of other cardiac glycosides co-existing in the leaves cannot be evaluated precisely.

In those assays, we utilized alkaline hydrolysis and hydrolysis with digilanidase. Alkaline hydrolysis of LC is considered to produce DLC by deacetylation. Therefore, in the present work, we first established a simultaneous HPLC-UV method to determine LC, DLC, ADx and Dx in D. lanata leaves, using a reversed phase $\mathrm{C}_{18}$ column. Then, we used the developed procedure to examine the effectiveness of various pretreatments for maximizing recovery of Dx from the leaves.

\section{Materials and Methods}

\subsection{Materials}

Dx, LC and DLC were obtained from Aldrich (Milwaukee, WI, U.S.A.), Merck (Darmstadt, Germany) and the National Institute of Hygenic Sciences (Japan), respectively. ADx and $\beta$-methyldigoxin (MDx; used as an internal standard, IS) were obtained from Boehringer Mannheim (Mannheim, Germany). Acetic acid and sodium methoxide were purchased from Wako Pure Chemical Industries, Ltd. (Osaka, Japan). Methanol (HPLC grade) and acetonitrile (HPLC grade) were purchased from Kanto Chemical Co., Inc. (Tokyo, Japan).

\subsection{Chromatographic Conditions}

The HPLC system comprised a model L-7110 pump (Hitachi, Tokyo, Japan), a Rheodyne injection valve (Cotati. CA, USA) with a 20- $\mu \mathrm{L}$ loop, and a model L-7405 UV detector (Hitachi) operating at UV wavelength of 220 $\mathrm{nm}$. The HPLC column (Cosmosil 5C $\mathrm{C}_{18}$-AR-300, Nacalai Tesque, Kyoto) was $150 \times 4.6 \mathrm{~mm}$ i.d., packed with 5 $\mu \mathrm{m}$ particles of $\mathrm{C}_{18}$ material. Quantification of the peaks was performed using a Model D-2500 chromato-integrator (Hitachi). The mobile phase consisted of acetonitrile: methanol: ultrapurewater (Milli-Q water purification system, Simplicity ${ }^{\circledR}$ UV, Millipore Corporation, Bedford, MA, USA) $=10: 100: 90(\mathrm{v} / \mathrm{v} / \mathrm{v})$. The samples were eluted from the column at room temperature at a flow rate of $0.5 \mathrm{~mL} / \mathrm{min}$. An aliquot of 15 to $20 \mu \mathrm{L}$ was injected into the HPLC system.

\subsection{Plant Materials}

D. lanata leaves were collected during the flowering stage in June 2000 at the Medical Plant Garden (Kanazawa, 
Japan) of Hokuriku University. The plants were obtained from Takeda Pharmaceutical Company Ltd. in June, 1976. The color and size of flowers have not been changed morphologically. The fresh leaves were immediately freeze-dried and then dried over $\mathrm{P}_{2} \mathrm{O}_{5}$ under reduced pressure at room temperature. The dried leaves were pulverized and sifted through a sieve of mesh width $500 \mu \mathrm{m}$. The dried leaf powder was further dried over $\mathrm{P}_{2} \mathrm{O}_{5}$ under reduced pressure for 5 days.

\subsection{Standard Solutions}

LC, DLC, ADx and Dx (each ca $2.5 \mathrm{mg}$ ) were each accurately weighed and dissolved in methanol (100 mL). Various volumes of prepared cardiac glycoside solution were added to $2 \mathrm{~mL}$ of MDx (IS) solution in methanol $(18.81 \mathrm{mg} / 250 \mathrm{~mL})$ to prepare standard solutions. Standard curves were obtained as described below.

\subsection{Sample Preparation}

The previous methods were modified for sample preparation [2] [3]. Briefly, dried leaf powder (ca. $50 \mathrm{mg}$ ) was accurately weighed and extracted with $50 \%$ methanol $(1 \mathrm{~mL})$. After ultrasonication for $1 \mathrm{~h}$ in an ultrasonic cleaning bath at room temperature, the extract was filtered through a filter paper (No. 2, ADVANTEC, Toyo Roshi Ltd., Tokyo, Japan) on a funnel fused-in fritted glass disc (SIBATA, Soka, Saitama, Japan). The residue was extracted with $50 \%$ methanol $(1 \mathrm{~mL})$ three times and filtered. Methanol $(40 \mu \mathrm{L})$, acetic acid $(50 \mu \mathrm{L})$, water $(5 \mathrm{~mL})$ and IS (75.24 $\mu \mathrm{g}, 2 \mathrm{~mL}$ ) were added to the combined filtrate and the mixture was applied to a Sep-Pak $\mathrm{C}_{18}$ cartridge (Waters). Methanol $(5 \mathrm{~mL})$ and water $(5 \mathrm{~mL})$ was used to activate the cartridge, which was then washed with $15 \%$ acetonitrile $(30 \mathrm{~mL})$. Target compounds were eluted with $30 \%$ acetonitrile $(10 \mathrm{~mL})$. Aliquots of the eluate (15 to $20 \mu \mathrm{L}$ ) were injected into the HPLC system.

\subsection{Enzymatic Hydrolysis Procedure}

The sample (ca. $50 \mathrm{mg}$ ) was accurately weighed and suspended in $0.05 \%$ acetic acid $3 \mathrm{~mL}$. The suspension was incubated at $2 \mathrm{~h}$ for $50^{\circ} \mathrm{C}$, and $50 \%$ methanol $(1 \mathrm{~mL})$ was added. The mixture was sonicated for $1 \mathrm{~h}$. Then, the same procedure was repeated.

\subsection{Alkaline Hydrolysis Procedure}

A sample (ca. $50 \mathrm{mg}$ ) was extracted with $50 \%$ methanol $(1 \mathrm{~mL})$ with the aid of ultrasonication three times, fol-lowed by filtration as above ("Sample Preparation”). The residue was extracted with $2.8 \%$ sodium methoxide in methanol $(40 \mu \mathrm{L})$ at $60^{\circ} \mathrm{C}$ for $2 \mathrm{~h}$ and filtered. Then, the same procedure was repeated.

\subsection{Combination of Pretreatments}

The sample (ca. $50 \mathrm{mg}$ ) was accurately weighed and suspended in $0.05 \%$ acetic acid $3 \mathrm{~mL}$. The suspension was incubated at $2 \mathrm{~h}$ for $50^{\circ} \mathrm{C}$, and $50 \%$ methanol $(1 \mathrm{~mL})$ was added. After ultrasonication for $1 \mathrm{~h}$ in an ultrasonic cleaning bath, the suspension was filtered. The residue was extracted with $50 \%$ methanol $(1 \mathrm{~mL})$ three times and the solution was filtered. Next, $2.8 \%$ sodium methoxide in methanol $(40 \mu \mathrm{L})$ was added to the combined filtrate and the mixture was incubated at $60^{\circ} \mathrm{C}$ for $2 \mathrm{~h}$. Then, the same procedure was repeated.

\subsection{Data Analysis}

Analytical data were expressed as mean \pm S.D. $(n=5)$. S.D. $=\sqrt{\frac{\sum\left(x_{\text {mean }}-x_{i}\right)^{2}}{n-1}}$.

\section{Results and Discussion}

\subsection{Standard Curves}

The chemical structures and molecular weights of LC, DLC, ADx, Dx and MDx are shown in Figure 1. A typical chromatogram is shown in Figure 2. Retention times of DLC, LC, Dx, ADx and IS were 8.4, 11.9, 12.9, 20.1 and $22.9 \mathrm{~min}$, respectively. Standard curves of the four cardiac glycosides were constructed by plotting five 


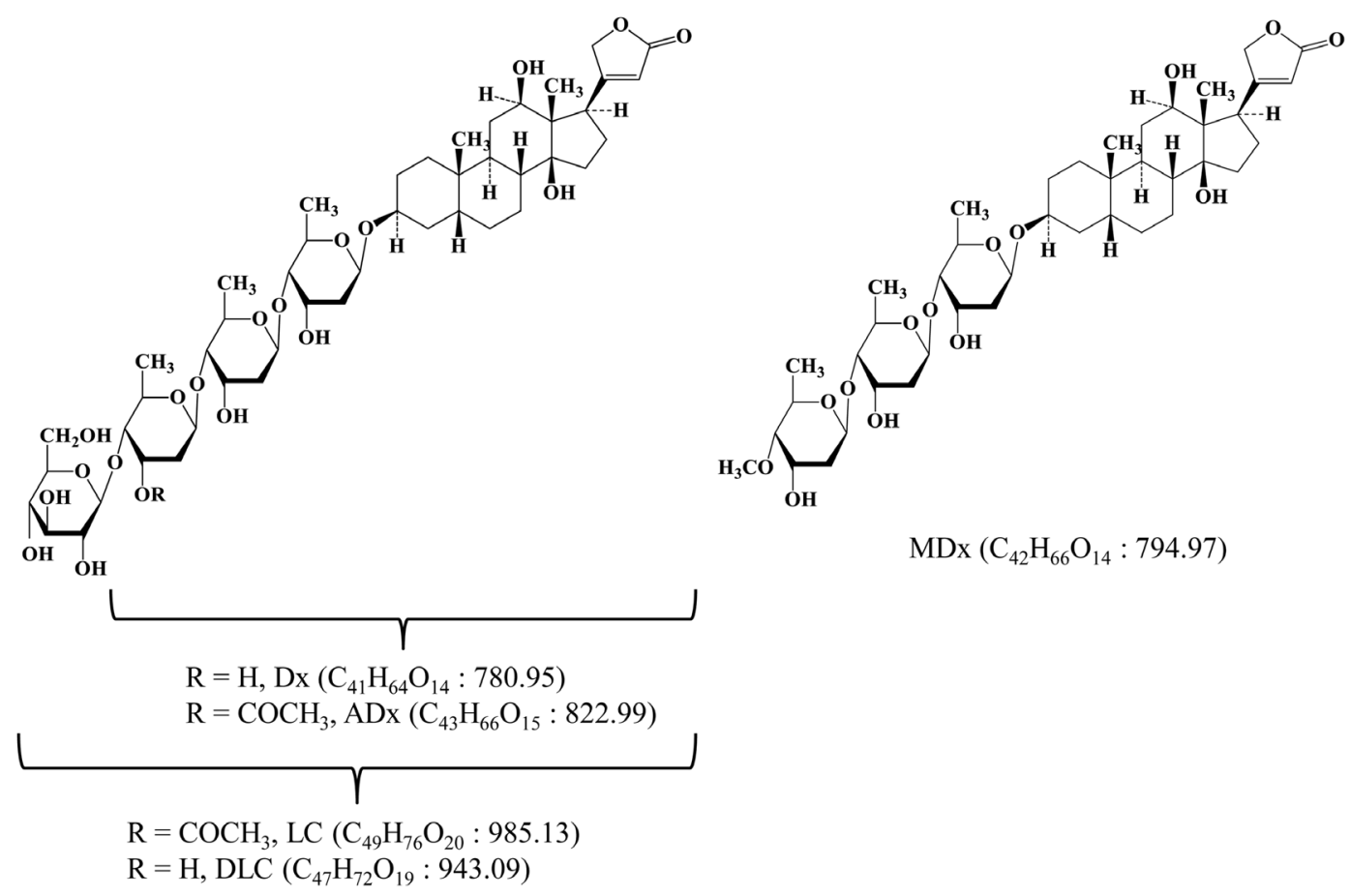

Figure 1. Chemical structures and molecular weights of cardiac glycosides.

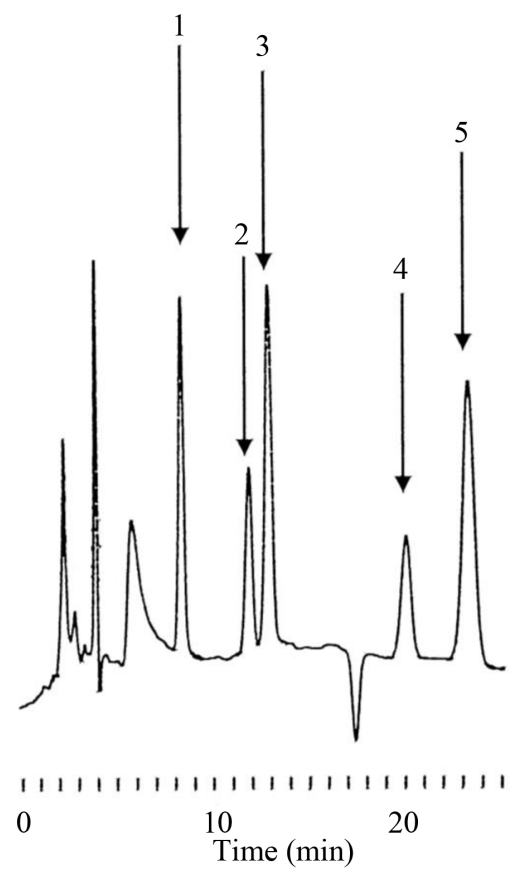

Figure 2. Typical chromatogram of DLC, LC, Dx, ADx and MDx. The retention times of DLC (1), LC (2), Dx (3), ADx (4) and MDx (5) were 8.4, 11.9, 20.1 and 23.2, respectively. MDx (5) was used as the IS.

or six data points. The regression lines were $y=0.008331 x-0.002581$ for DLC with a correlation coefficient $(r)$ of 0.9988 (range $24.74-123.7 \mu \mathrm{g}), y=0.005854 x-0.001715$ for LC ( $r=0.9996$, range $26.00-130.0 \mu \mathrm{g}), y=$ $0.010359 x-0.010774$ for Dx $(r=0.9994$, range $25.58-127.9 \mu \mathrm{g}), y=0.009472 x-0.001506$ for $\mathrm{ADx}(r=$ 0.9993 , range 16.16 - $161.6 \mu \mathrm{g}$ ), where $y$ represents the peak area ratio of each cardiac glycoside to the IS and $x$ represents the amount $(\mu \mathrm{g})$ added in preparing the standard solutions. 


\subsection{Amounts of Cardiac Glycosides in D. lanata Leaves}

A typical chromatogram of cardiac glycosides obtained from D. lanata leaves is shown in Figure 3. LC, Dx and ADx were detected, and their amounts per $100 \mathrm{mg}$ of leaves were estimated to be $115.6 \pm 1.8,7.45 \pm 0.40$ and $23.8 \pm 1.2 \mu \mathrm{g}$ (mean \pm S.D.; $n=5$ ), respectively (Table 1 ). These values correspond to 117.3, 9.5 and $28.9 \mathrm{nmol}$, and total cardiac glycosides amounted to $155.7 \mathrm{nmol}$. DLC was not detected.

\subsection{Enzymatic Hydrolysis}

The powder suspended in $0.05 \%$ acetic acid as a pretreatment, which is considered to activate digilanidase present in the leaves. The amounts of Dx and ADx per $100 \mathrm{mg}$ of leaves after the pretreatment were estimated to be $21.1 \pm$ 8.0 and $52.1 \pm 7.5 \mu$ g (mean \pm S.D.; $n=5$ ), respectively (Table 2). These values correspond to 27.0 and 63.3 nmol. DLC and LC were not detected (data not shown). Total recovery was 58.0\% compared with the control.

\subsection{Alkaline Hydrolysis}

Addition of sodium methoxide to the residue of the powder extracted with $50 \%$ methanol is considered to cause hydrolysis of ester. The amounts of DLC and Dx per $100 \mathrm{mg}$ of leaves after the pretreatment were estimated to be $65.6 \pm 1.4$ and $20.9 \pm 0.4 \mu \mathrm{g}$ (mean \pm S.D.; $n=5$ ), respectively (Table 3). These values correspond to 69.6 and 20.9 nmol. LC and ADx were not detected (data not shown). Total recovery was 61.9\% compared with the control.

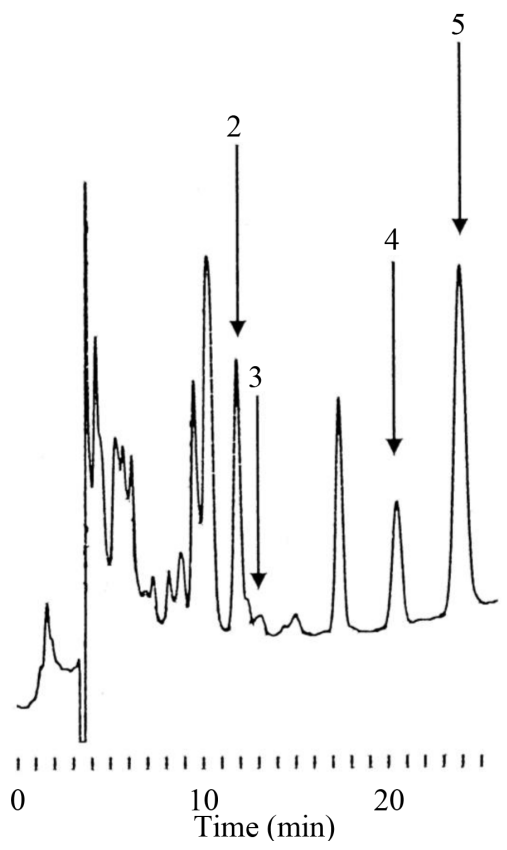

Figure 3. Typical chromatogram of cardiac glycosides from D. lanata leaves. LC (2), Dx (3) and ADx (4) were determined. MDx (5) was used as the IS.

Table 1. LC, Dx and ADx amounts per $100 \mathrm{mg}$ of $D$. lanata leaves.

\begin{tabular}{cccc}
\hline Experimental number & $\begin{array}{c}\mathrm{LC} \\
(\mu \mathrm{g} / 100 \mathrm{mg})\end{array}$ & $\begin{array}{c}\mathrm{Dx} \\
(\mu \mathrm{g} / 100 \mathrm{mg})\end{array}$ & $\begin{array}{c}\text { ADx } \\
(\mu \mathrm{g} / 100 \mathrm{mg})\end{array}$ \\
\hline 1 & 116.0 & 7.77 & 23.7 \\
2 & 117.8 & 7.05 & 23.1 \\
3 & 114.7 & 7.61 & 25.5 \\
4 & 113.7 & 7.74 & 22.4 \\
5 & 116.6 & 7.07 & 24.2 \\
Mean \pm S.D. (R.S.D.) & $115.6 \pm 1.8$ & $7.45 \pm 0.36$ & $23.8 \pm 1.2$ \\
\hline
\end{tabular}




\subsection{Combination of Pretreatments}

Based on the above results, we speculated that the combination of both pretreatments would allow us to isolate digoxin alone from $D$. lanata leaves. Indeed, only Dx was detected after the combined pretreatments, as shown in Figure 4, and the amount of digoxin per $100 \mathrm{mg}$ of the leaves was estimated to be $115.1 \pm 11.7 \mu \mathrm{g}$ (mean \pm S.D.; $n=5$ ) (Table 4). Thus, compared with the control, the Dx level was increased about 15 -fold.This amount of Dx corresponds to $147.4 \mathrm{nmol}$, and the recovery was $94.7 \%$ compared with the control. Thus, the combination

Table 2. Dx and ADx amounts per $100 \mathrm{mg}$ of D. lanata leaves after the pretreatment with acetic acid.

\begin{tabular}{ccc}
\hline Experimental number & $\begin{array}{c}\text { Dx } \\
(\mu \mathrm{g} / 100 \mathrm{mg})\end{array}$ & $\begin{array}{c}\text { ADx } \\
(\mu \mathrm{g} / 100 \mathrm{mg})\end{array}$ \\
\hline 1 & 11.5 & 61.1 \\
2 & 20.2 & 58.9 \\
3 & 17.9 & 49.5 \\
4 & 22.5 & 47.3 \\
5 & 33.3 & 13.7 \\
Mean \pm S.D. (R.S.D.) & $21.1 \pm 8.0$ & $52.1 \pm 7.5$ \\
\hline
\end{tabular}

Table 3. DLC and Dx amounts per $100 \mathrm{mg}$ of $D$. lanata leaves after the pretreatment with sodium methoxide.

\begin{tabular}{ccc}
\hline Experimental number & $\begin{array}{c}\text { DLC } \\
(\mu \mathrm{g} / 100 \mathrm{mg})\end{array}$ & $\begin{array}{c}\text { Dx } \\
(\mu \mathrm{g} / 100 \mathrm{mg})\end{array}$ \\
\hline 1 & 64.2 & 25.0 \\
2 & 65.2 & 19.6 \\
3 & 65.0 & 21.5 \\
4 & 65.7 & 21.3 \\
5 & 67.9 & 17.2 \\
Mean \pm S.D. (R.S.D.) & $65.6 \pm 1.4$ & $20.9 \pm 0.4$ \\
\hline
\end{tabular}

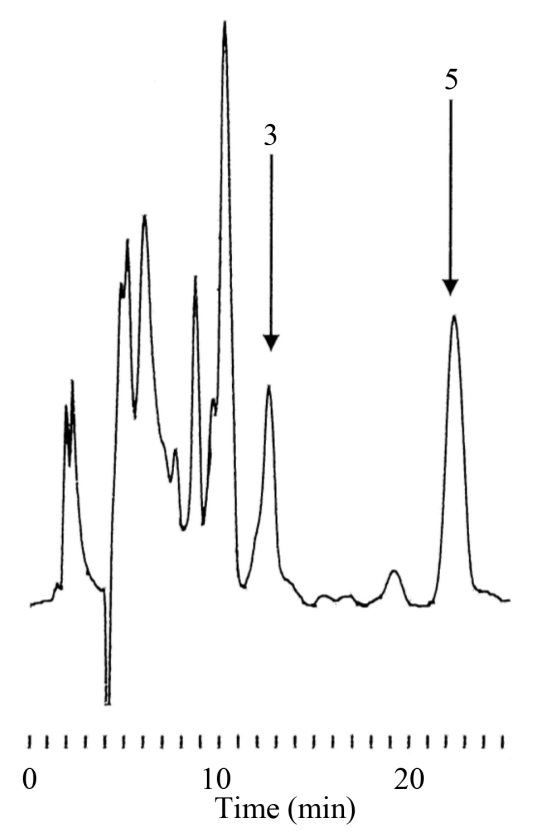

Figure 4. Typical chromatogram of sample of cardiac glycosides from $D$. lanata leaves after the combination of pretreatments. Only Dx (3) was determined, while DLC, LC and ADx were not detected. MDx (5) was used as the IS. 
Table 4. DLC and Dx amounts per $100 \mathrm{mg}$ of D. lanata leaves after the combined pretreatment with acetic acid and sodium methoxide.

\begin{tabular}{cc}
\hline Experimental number & $\begin{array}{c}\mathrm{Dx} \\
(\mu \mathrm{g} / 100 \mathrm{mg})\end{array}$ \\
1 & 101.5 \\
2 & 122.8 \\
3 & 105.2 \\
4 & 129.5 \\
5 & 116.3 \\
Mean \pm S.D. (R.S.D.) & $115.1 \pm 11.7$ \\
\hline
\end{tabular}

of these pretreatments provides excellent recovery of Dx from the leaves. It remains to be established whether other cardiac glycosides in the leaves are also converted to Dx by these pretreatments, thereby contributing to the high recovery.

\section{Conclusion}

The combination of pretreatments with acetic acid and sodium methoxide enabled recovery of Dx from $D$. $l a$ nata leaves at the level of $115.1 \mu \mathrm{g} / 100 \mathrm{mg}$ leaves, as compared with $7.45 \mu \mathrm{g} / 100 \mathrm{mg}$ leaves in the absence of any pretreatment. These results indicate that this combination of pretreatments is effective for maximizing the yield of Dx from D. lanata leaves.

\section{References}

[1] Gisvold, O. and Wright, S.E. (1957) Enzymatic Decomposition of Digitalis Glycosides. Journal of the American Pharmaceutical Association, 46, 535-538. http://dx.doi.org/10.1002/jps.3030460906

[2] Ikeda, Y., Fujii, Y. and Yamazaki, M. (1991) Determination of Lanatoside C and Digoxin in Digitalis lanata by HPLC and Its Application to Analysis of the Fermented Leaf Powder. Journal of Natural Products, 55, 748-752. http://dx.doi.org/10.1021/np50084a007

[3] Ikeda, Y., Fujii, Y. and Yamazaki, M. (1991) High-Performance Liquid Chromatographic Determination of a-Acetyldigoxin in Digitalis lanata Leaves. Analytical Biochemistry, 196, 451-455. http://dx.doi.org/10.1016/0003-2697(91)90493-D

[4] Cobb, P.H. (1976) Application of High-Performance Liquid Chromatography to the Separation of Cardenolides and the Assay of Digoxin in Digitalis lanata Leaf. Analyst, 101, 768-776. http://dx.doi.org/10.1039/an9760100768

[5] Pekić, B. and Miljković, D. (1975) A New Method of Preparation of Deacetyl-Lanatosides. Planta Medica, 27, 178-181. http://dx.doi.org/10.1055/s-0028-1097782

[6] Hirabayashi, H., Sugimoto, H., Matsumoto, S., Amano, N. and Moriwaki, T. (2011) Development of a Quantification Method for Digoxin, a Typical P-Glycoprotein Probe in Clinical and Non-clinical Studies, Using High Performance Liquid Chromatography-Tandem Mass Spectrometry: The Usefulness of Negative Ionization Mode to Avoid Competitive Adduct-Ion Formation. Journal of Chromatography B, 879, 3837-3844. http://dx.doi.org/10.1016/j.jchromb.2011.10.031

[7] Guan, F. Akira Ishii, A., Seno, H., Watanabe-Suzuki, K., Kumazawa, T. and Suzuki, O. (1999) Identification and Quantification of Cardiac Glycosides in Blood and Urine Samples by HPLC/MS/MS. Analytical Chemistry, 71, 4034-4043. http://dx.doi.org/10.1021/ac990268c

[8] Kwon, H.J., Sim, H.J., Lee, S.I., Lee, Y.M., Park, Y.D. and Hong, S.P. (2011) HPLC Method Validation for Digitalis and Its Analogue by Pulsed Amperometric Detection. Journal of Pharmaceutical and Biomedical Analysis, 54, 217221. http://dx.doi.org/10.1016/j.jpba.2010.07.037

[9] Ikeda, Y., Araki, T., Takimoto, H. and Fujii, Y. (2002) Development of Radioimmunoassay for Measurement of Serum Digoxin in Digitalized Patients Using Novel Anti-Digoxin Antiserum. Biological and Pharmaceutical Bulletin, 25, 422-425. http://dx.doi.org/10.1248/bpb.25.422

[10] Ikeda, Y, and Fujii, Y. (2005) Properties of Novel Anti-Digoxin Antisera in Radioimmunoassay Using Homologous and Site Heterologous Tritium-labeled Antigens Involving a $\left[{ }^{3} \mathrm{H}\right]$-Leucine Moiety. Biological and Pharmaceutical Bulletin, 28, 340-343. http://dx.doi.org/10.1248/bpb.28.340

[11] Higashi, Y., Ikeda, Y., Yamamoto, R., Yamashiro, M. and Fujii, Y. (2005) Pharmacokinetic Interaction with Digoxin 
and Glucocorticoidsin Rats Detected by Radio-immunoassay Using a Novel Specific Antiserum. Life Science, 77, 1055-1067. http://dx.doi.org/10.1016/j.lfs.2005.03.003

[12] Higashi, Y., Ikeda, Y., Yamamoto, N. and Fujii, Y. (2015) Establishment of a Highly Specific Enzyme Immunoassay for Digoxin in Human Serum. Jacobs Journal of Nanomedicine and Nanotechnology, 1, 1-6. 